\title{
Prosthodontic Management of Single Complete Denture with Reinforced Metal Denture Base: A Case Report
}

\author{
Chhavi Sharma ${ }^{1} \quad$ Manjit Kumar $^{1} \quad$ Ajay Bansal ${ }^{1}$ Sanjan Verma ${ }^{1} \quad$ Shak Mehta ${ }^{1}$ \\ ${ }^{1}$ Department of Prosthodontics, Bhojia Dental College, Baddi, \\ Solan, Himachal Pradesh, India \\ Address for correspondence Chhavi Sharma, MDS, Department \\ of Prosthodontics, Bhojia Dental College, Baddi, Solan 173205, \\ Himachal Pradesh, India (e-mail: cshrma1026@gmail.com).
}

Dent J Adv Stud 2019;7:42-45

\begin{abstract}
Keywords

- complete denture

- metal denture base

- polymer resin

For improvement in longevity of complete denture prosthesis in place of conventional poly methyl methacrylate denture base material, metal denture base is used to rehabilitate complete edentulous maxillary arch as it helps in preventing resorption of residual ridges and improves fracture resistance, better dimensional stability, more accuracy, less weight, and better retention of prosthesis. For better prognosis there are many factors, but major factors such as retention, stability, and support are more important. Metal denture base leads to improvement in physical properties of the prosthesis.
\end{abstract}

\section{Introduction}

According to French, artificial dentures function like mechanical machines in an anatomic environment. In cases in which there is a clash between esthetic and functional requirements, a choice is to be made by favoring one at the expense of the other or make some amount of compromises in most situations. ${ }^{1}$ Polymers are the dominant material for the fabrication of denture bases. Materials such as polymethyl methacrylate may be molded and polymerized by use of a variety of techniques. These polymeric bases present acceptable physical, biologic, and esthetic characteristics at moderate expense. However, there are instances in which these bases fail because of poor denture base adaptation. Failure may also be caused by excessive masticatory forces when we fabricate single complete denture against the natural and fixed dentition. In those situations, metal alloys have been used to strengthen the bases and prevent fracture. ${ }^{2}$

To increase rigidity and fracture resistance, metals and metal alloys are cast into thin sheets and incorporated in denture bases. ${ }^{3}$ Interference with phonation also get decrease due to thinner metallic denture base. ${ }^{4}$ These bases are more accurate and dimensionally stable. ${ }^{5}$ Being highly thermal conductive property of metal denture base is responsible for enhancing tissue health with their contact. ${ }^{6}$

Procedure of fabrication of metal denture base is not cost-effective and not complicated. The junction of resin and metal should be carefully located and formed to ensure proper palatal contour and to reduce weight and maximum strength.?

\section{Case Report}

A 45-year-old male patient reported to the Department of Prosthodontics, Bhojia Dental College and Hospital, Baddi, with a chief complaint of upper completely missing teeth. The patient also complained about fracture of upper denture. In the past dental history, he got treated with 14 units fixed dental prosthesis in the lower arch and denture for the upper arch. Detailed case history was recorded, and no significant

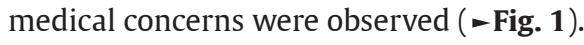

\section{Intraoral Examination}

Intraoral examination revealed completely edentulous maxillary ridge and opposing 14 units fixed dental prosthesis. According to Len Tolstunov classification, the patient was classified under class I modification 2 condition in which the upper arch was completely edentulous with stable fixed full dentition in the mandibular arch. Mucosa was normal, and opposing prosthesis required minor alterations. Saliva was of medium consistency, and the patient was cooperative and philosophical. The patient had class II (medium) arch size with square arch form according to house classification. The received

September 26, 2018 accepted after revision

February 11, 2019

published online

April 5, 2019
DOI https://doi.org/

10.1055/s-0039-1685126 ISSN 2321-1482.
(C)2019 Bhojia Dental College and

Hospital affiliated to Himachal Pradesh University
License terms

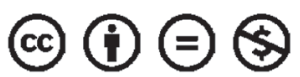



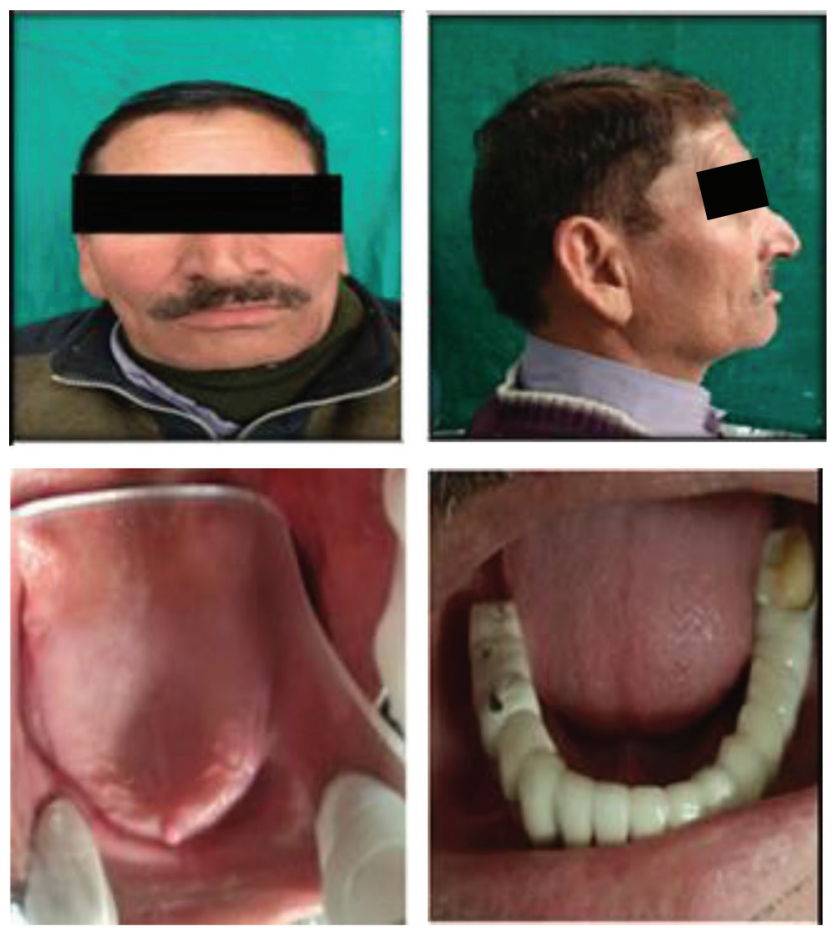

Fig. 1 Preoperative extra- and intraoral views of patient.

patient's ridge was high with flat crest and parallel sides. His hard palate was U-shaped with class I soft palate that was horizontal and demonstrated little muscular movement. In this case, more tissue coverage was possible for posterior palatal seal.

\section{Treatment Procedure}

Preliminary impression of the edentulous maxilla was made with impression compound (Rolex, Delhi, India) and was poured with plaster of paris (Dentex, Jammu, India) for the fabrication of a custom special tray. The peripheral tracing procedures were completed with green stick impression compound (DPI Pinnacle, Mumbai, India), and the secondary impression was made with zinc oxide eugenol impression material (DPI Impression Paste, Mumbai, India). Master cast was poured with dental stone (Kala Bhai, Mumbai, India) type III (-Fig. 2).

Duplication of master cast was done by using reversible hydrocolloid AGAR impression material (Wirodouble, Bremen, Germany) and poured with refractory material (Kala Bhai Ultrarock, Mumbai, India). Wax pattern (Yeti, Engen, Germany) was made on refractory cast invested with phosphate-bonded investment material (Dellodent, Japan), and casting was done. Metal denture base was fabricated (-Fig. 3).

Trial denture base and occlusion rim were fabricated. At this stage, jaw relation records were used to mount and verify the positions of maxillary and mandibular casts. After mounting, tooth arrangement was done according to anatomic, functional, and esthetic guidelines by establishing bilateral balanced occlusion. Adjustments in the artificial teeth were incorporated in preference to making natural
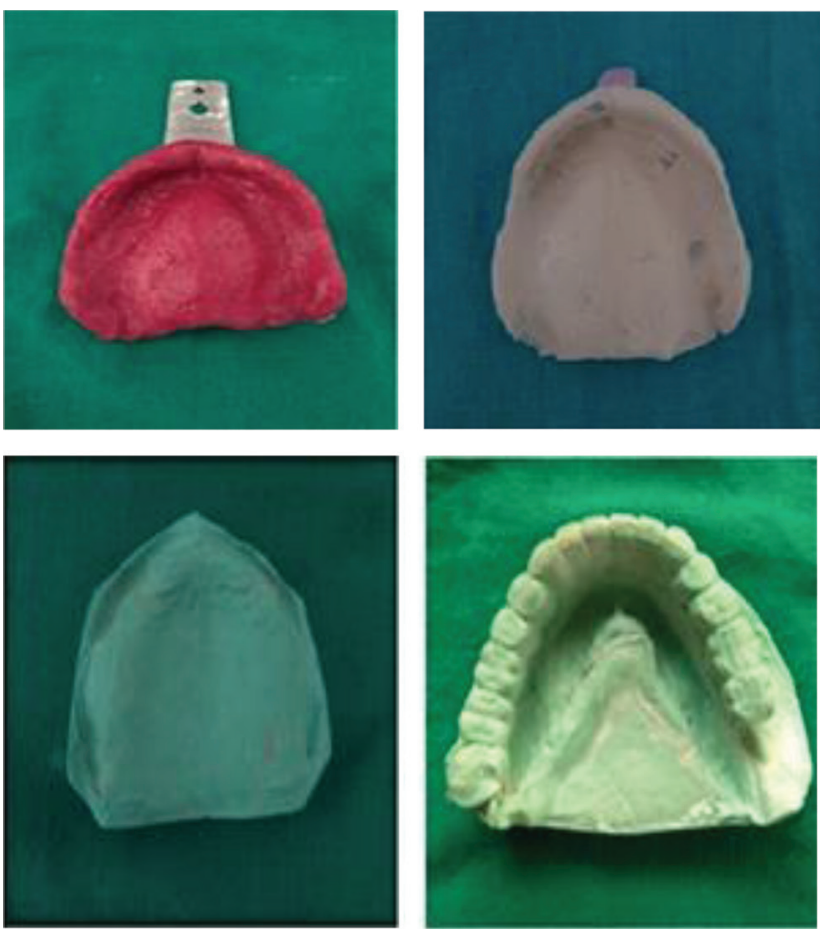

Fig. 2 Impressions and casts.
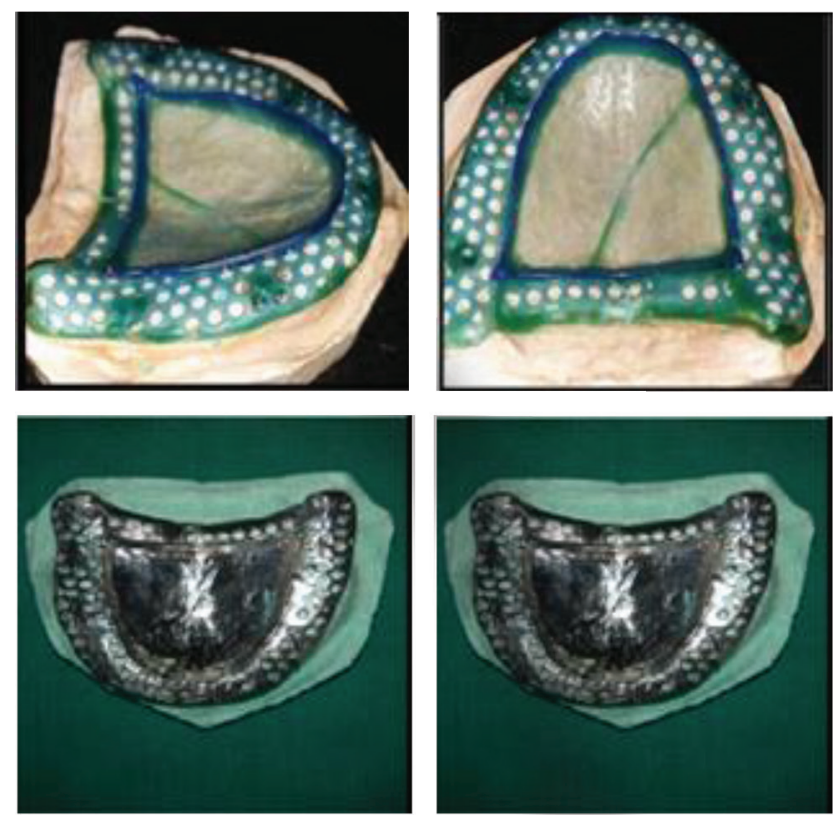

Fig. 3 Wax patterns and metal denture base.

teeth. Though a perfect balanced occlusion is impossible to achieve in such cases with involvement of fixed dental prosthesis in opposing arch, a maximum effort was made to get an occlusion that was as close to balanced occlusion. Trial of the denture was done ( - Fig. 4 ).

Denture fabrication was done with conventional method using heat cure resin poly methyl methacrylate (DPI Heat Cure, Mumbai, India) by keeping metal framework at the respective maxillary cast. A butt joint was created palatal to the crest at the junction of acrylic and metal to enhance the 

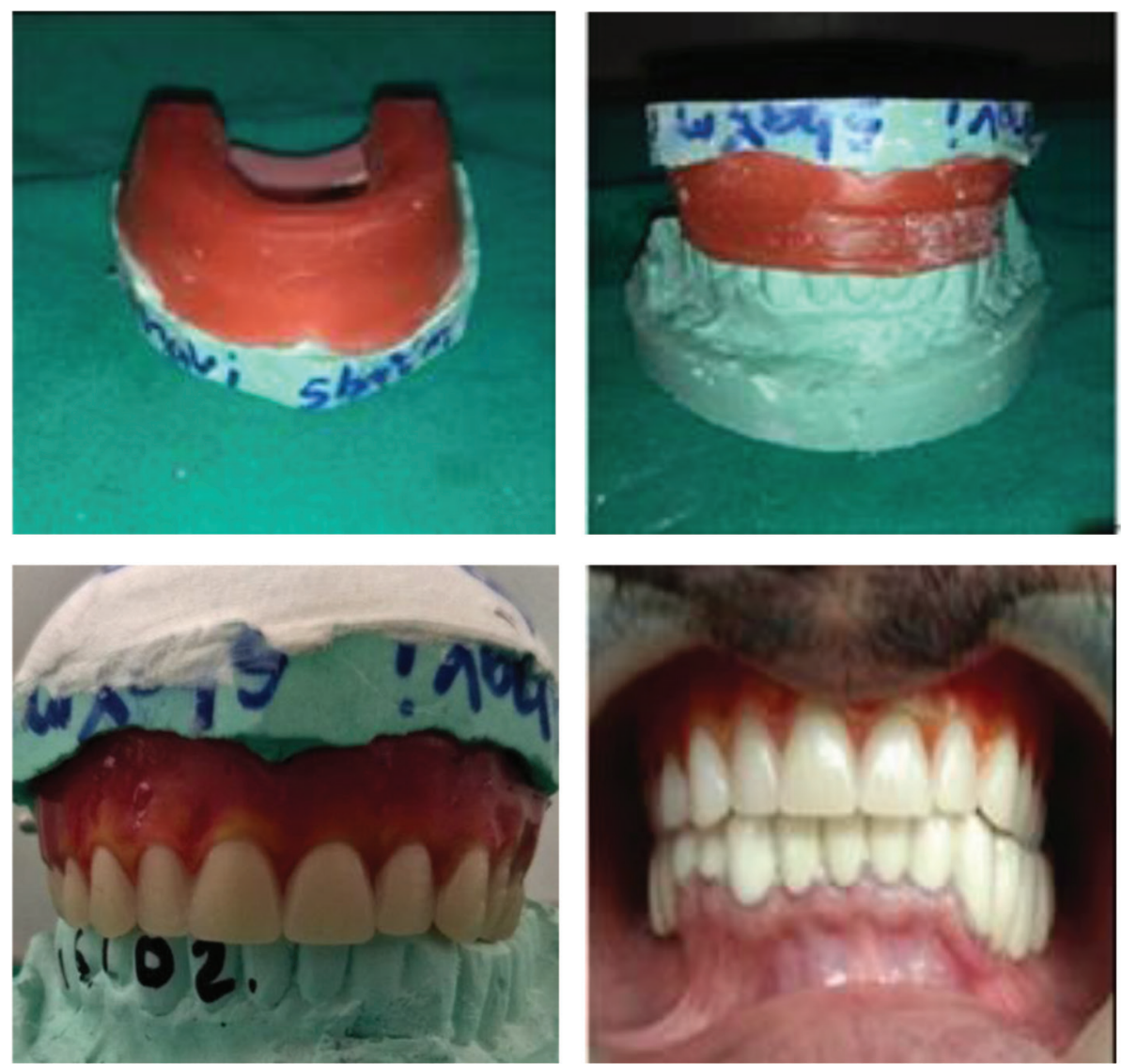

Fig. 4 Jaw relation and trial denture base.

strength of metal acrylic junction. This helps in creating a smooth joining of acrylic with metal avoiding any step formation, thus making it comfortable for the patient. Maxillary denture was inserted into the patient's mouth after the occlusal adjustment, and proper care and maintenance of the prosthesis instructions were given to the patient ( - Fig. 5).

\section{Discussion}

The part of a complete or removable partial denture that rests upon the basal seat and to which the teeth are attached is known as denture base.
According to (GPT 9), Metal Base is defined as the metallic portion of a denture base forming a part or the entire basal surface of the denture; it serves as a base for the attachment of the resin portion of the denture base and the teeth.

Major indication of complete denture reinforced metal base where patients with natural dentition or fixed dental prosthesis in opposing arch as presence of unmodified opposing dentition prevents occlusal balance during function, thereby compromising stability and retention and eventually leading to frequent mechanical failures of the prosthesis. Any factor that exacerbates the deformation of the base or alters its stress distribution may predispose the polymethyl
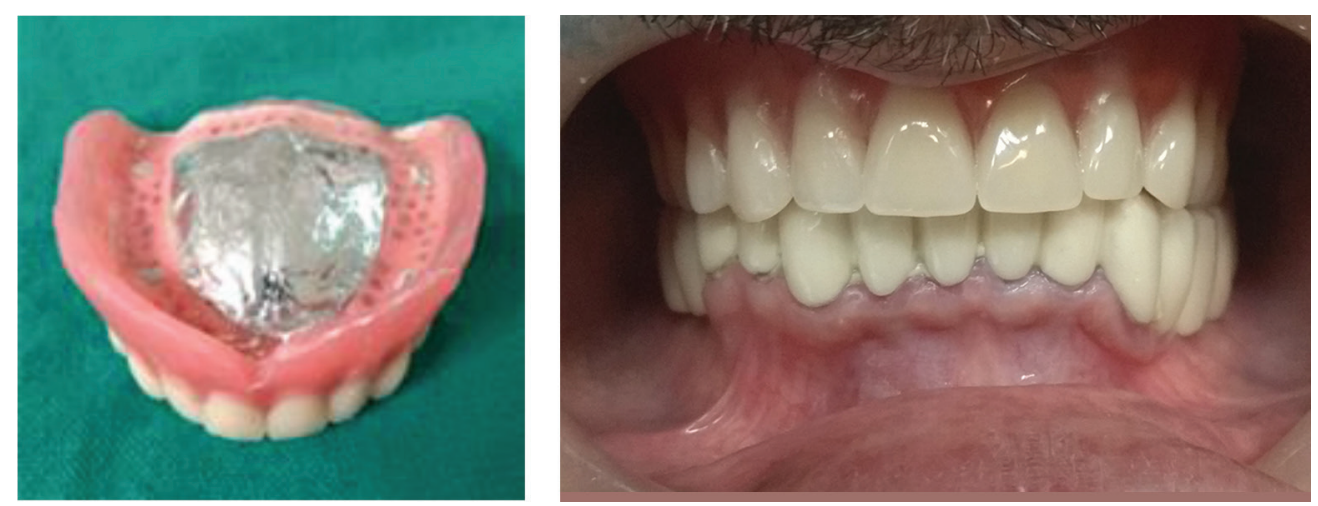

Fig. 5 Acrylised metal denture base and denture insertion. 
methacrylate denture to fracture. In patients with high or low position of palatal surface, when the actual center of the denture was at a significant distance from the "ideal" center of the denture, no tori palatini as well as exostosis or bony prominences were present, and in unilateral residual ridge resorbed patients, inadequate interarch space was present. Other indications of metal denture base are tooth-supported partial dentures and where inadequate interarch space is present.

There are various ideal requirements of a denture base material that it should be biocompatible. Material should have good abrasion resistance as well as high thermal conductivity. Density and solubility and sorption to oral fluids should be less.

Cast metal denture bases have various advantages over acrylic bases; for example, they are light in weight with more strength compared to acrylic. During fabrication of denture, they also prevent warpage of prosthesis. They show more accurate fit and dimensional accuracy. Their high strength causes less chances of breakage. Reproduction of tissues details is more accurate, and under metal denture bases, less tissue changes occur. Metal denture bases exhibit better thermal conductivity, and they are less porous compared to acrylic. ${ }^{8}$

Denture with metal base is not only rigid and fracture resistance, but it also has good strength-to-volume ratio that makes it light weight. It is highly biocompatible. Thermal conductivity is more and enhances tissue health, less interferences with speech, and better adaptation to soft tissue. $^{9}$

This prosthesis is indicated when polymethylmethacrylate does not provide adequate physical properties. ${ }^{10}$

There are a few disadvantages regarding metal denture base: it is difficult to reline and rebase, it compromises esthetic qualities, and it is contraindicated in patients allergic to base metal alloys.

\section{Conclusion}

Treatment efficacy and effectiveness will depend on the knowledge of properties of different prosthodontic materials by the dentist. Metal denture bases are strong to resist destructive failure, help in providing comfort to the patient, and solve the problem of recurrent fractures. In addition, metal denture bases are good thermal conductor and light weight; thus, patients perceive natural feeling. Also, their thin base increases denture stability.

\section{Conflict of Interest}

None declared.

\section{References}

1 French FA. The problem of building satisfactory dentures. J Prosthet Dent 1954;4:769-781

2 Grunewald AH. Gold base lower dentures. J Prosthet Dent 1964;14:432-441

3 Phillips RW. Skinner's Science of Dental Materials. 9th ed. Philadelphia, PA: WB Saunders; 1991:177-213

4 Allen LR. Improved phonetics in denture construction. J Prosthet Dent 1955;8:753-763

5 Roth GJ. An analysis of articulate sounds and its use and application in the art and science of dentistry. Am J Orthod 1940;26(1):1-23

6 Craig RG. Restorative Dental Materials. 9th ed. St Louis, MO: Mosby-Year Book; 1993:502-550

7 Rothman R. Phonetics considerations in denture prosthesis. J Prosthet Dent 1961;11:214-223

8 Atwood DA. Final report on the clinical requirement of ideal denture base materials. JPD 1968;20:101

9 Lamb DJ, Ellis B, van Noort R. The fracture topography of acrylic dentures broken in service. Biomaterials 1985;6(2):110-112

10 Faber BL. Lower cast metal base. JPD 1957;7:51-54 